\title{
Review of "Forensic Engineering, Legal Considerations, and Property Damage Assessment from Construction Vibrations" by D.S. Saxena, Prashanth Vaddu and Anu Saxena
}

\author{
Mark Svinkin* \\ VIBRACONSULT, Cleveland, USA
}

*Corresponding author: Mark Svinkin, VIBRACONSULT, Cleveland, USA.

Email: msvinkin@roadrunner.com

Received Date: October 20, 2020

Published Date: November 13, 2020

Keywords: Construction vibrations; Damage; Settlement; Soil; Structures; Tolerable limits; Vibration measurement

\section{Introduction}

The paper contains a brief description of forensic investigations of failures and short information on a case history of damage to structures from construction vibrations [1]. The review focuses on the case history which is fully presented in Svinkin and Saxena [2]. The reviewer wishes to bring attention to proper evaluation of vibration effects on structures. Detrimental consequences of construction vibrations are not only topic for academic interests. These effects create meaningful practical problems. Each year, numerous structures, and residential houses among them receive damage from construction operations, and these consequences result in litigations. It is necessary to professionally manage construction vibrations, and sensible vibration limits are important for the control of construction vibrations.

\section{Construction Activities for the Project}

At the area of residential houses, a contractor constructed 4 Treatment Vaults (TV) and 33 Drainage Structures (culverts, inlets, etc.) at four different locations. The excavation depth was 3.9-4.8 $\mathrm{m}$ for treatment vaults and 1.2-6.1 $\mathrm{m}$ for drainage structures. All locations of construction sites and surrounding residential areas had similar soil conditions. Boring was performed to the depth of $10 \mathrm{~m}$. The soil deposits to the depth of $9.0 \mathrm{~m}$ consisted of moist poorly graded loose to medium dense slightly silty sand with layers of about $0.9-1.5 \mathrm{~m}$ of silty clayey sand at two locations. The ground water table level was observed at the depth of 3.9-5.4 $\mathrm{m}$ for three houses at the TV5 site and for one house at the TV4 site. Also, water was not encountered for two houses at the TV4 site. Steel sheet piles were driven for construction of Treatment Vaults and Drainage Structures. PVE 1420 vibratory driver with PVE 280 power unit was used for driving and extraction of sheet piles. The model has the maximum frequency of $2000 \mathrm{rpm}$. Owners of houses located mostly in the neighborhood area of the TV4 and TV5 construction sites complained about various cracks in structures and other house damage occurred during construction operations specifically from vibratory sheet pile driving and extraction. Ground vibrations were measured at distances of 12.3, 15.0 and $150.0 \mathrm{~m}$ from construction operations at TV4 site. PPV of ground vibrations was in the 4.6-11.4 $\mathrm{mm} / \mathrm{sec}$ range at close distanced from the dynamic sources and much smaller (0.01-0.02 mm/sec) at far away distance. The houses 
with alleged damage located at distances from 9 to $165 \mathrm{~m}$ from the construction sites.

\section{Field Forensic Investigations}

These investigations involved a two-stage program.

\section{Stage 1 Program}

"It consisted of performing a forensic investigation at each of the 20 claim locations that included:

1. A geotechnical exploration

2. A visual condition surveys

3. An interview with the property owner

4. A field probing and coring program

5. Test pits and footing inspection

6. Appropriate samples were collected, and stability analysis were performed for each of the 20 residential structures."

This is complete information about forensic activities at the former construction sites. Unfortunately, no results of these investigations and tests at the site (condition surveys of houses with damage, interviews with homeowners, soil data, soil tests and foundation inspections) are presented in the paper. The results of forensic investigations are completely missing though investigations at these locations are important for analysis of damage to houses.

\section{Stage 2 Program}

For evaluation of different construction activities on generated ground vibrations, special vibration tests were performed at the "staging area" bordering with construction sites and similar soil conditions. The tests comprised driving two sheet piles in parallel and perpendicular mode to a line of four geophone placement, dropping a heavy collector section from a height about $1.5 \mathrm{~m}$, movement of heavy construction equipment along the geophone placement. The results of these tests presented in the paper. The maximum measured PPV was 7.6 and $10.2 \mathrm{~mm} / \mathrm{sec}$ in different tests.

\section{Damage Evaluation from Construction Vibrations}

In the United States, the U.S. Bureau of Mines (USBM) RI 8507 is the major document used for assessment of blasting effects on various structures, Siskind et al. [3]. The USBM vibration limits were developed for prevention of low frequency resonant horizontal vibrations of 1 and 2-story residential houses at big distances from surface coal mines, (Figure 1).

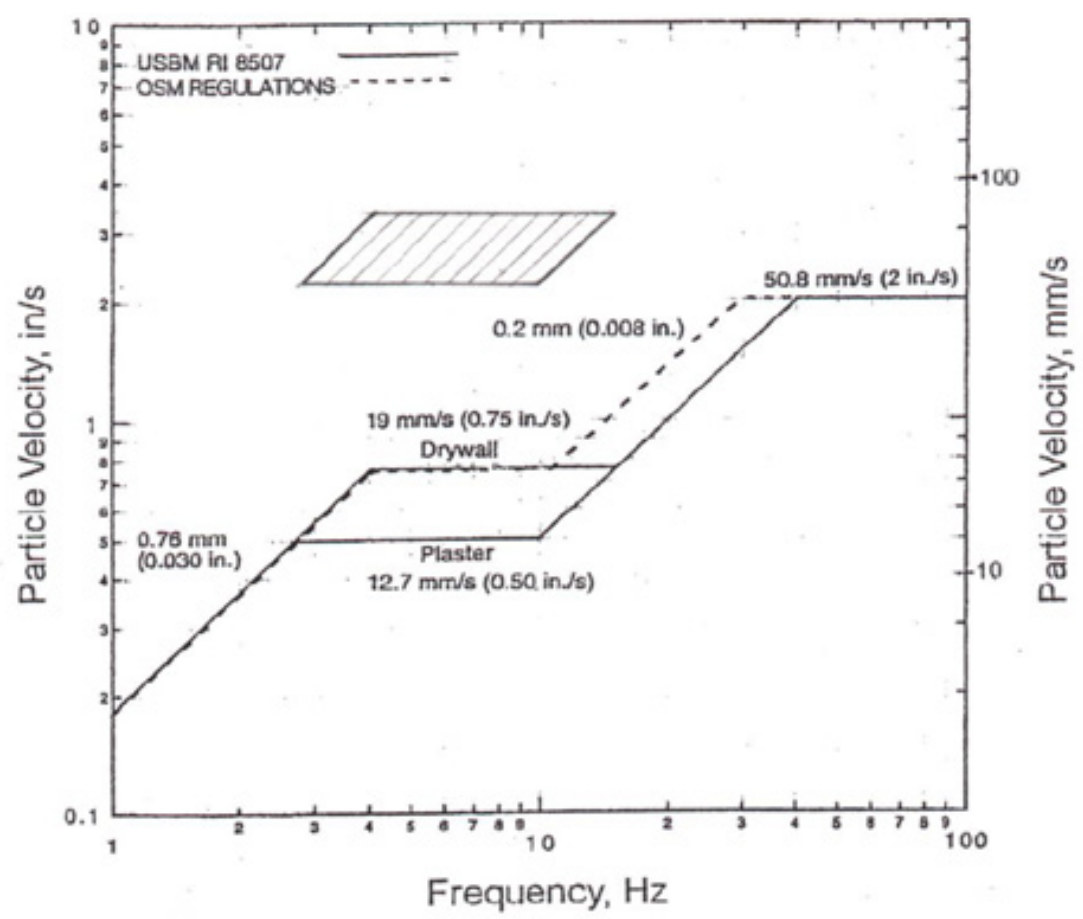

Figure 1: Safe level blasting criteria from USBM RI 8507 and the derivative version (dashed line shows the chart option from OSM surface coal mine regulations; shaded area shows maximum velocities of structural vibrations with amplification of 4.5 at resonance) (data from Siskind [7]; Svinkin [4]; with permission).

The problem was resolved, and the USBM RI 8507 was considered as the great achievement at that time. Obviously, it was the reason for the application of the USBM vibration limits for evaluation of vibration effects on various structures from any man-made vibrations. The authors used these criteria for assessment of construction vibration effects on residential houses 
because such an approach was used in the report prepared in 2004. Publication of the report results in that time was completely reasonable. Unfortunately, the paper was published in 2016 after the new obtained research results had shown that the USBM vibration limits have nothing to do with construction vibrations, Svinkin [4-6]. The first author was familiar with Svinkin [4,5]. The RI 8507 study focused on low-rise residential structures like one-two story houses adjacent to mining facilities and resulted in a guideline for prevention of cosmetic cracking and other structure damage. However, the application of such safe limits to construction vibration sources, different soil conditions, other superstructures, diverse underground structures and utilities is incorrect because a correlation between ground vibrations and structural damage works only for a combination of blasting, soil conditions and low-rise houses for which the correlation was obtained. Also, it is necessary to underline that the USBM RI 8507 have nothing to do with soil plastic deformations and dynamic settlements. Ground vibrations can affect structures in diverse ways. There are various structural responses to ground vibrations depending on soil-structure interaction. Elastic soil deformations can produce direct vibration effects on structures, trigger resonant soil layer vibrations and resonant structural vibrations of adjacent and remote structures. Plastic soil deformations can trigger soil densification and soil settlement beyond the densification zone.

Elastic and plastic soil deformations cause dissimilar structural responses and damage. Therefore, diverse thresholds should be used for assessment of direct vibration effects, resonant structural vibrations, and dynamic settlements. Direct vibration effects on structures are results of soil-structure interaction when frequencies of ground vibrations do not match natural frequencies of structures. Structures have substantial resistance to direct vibration effects. According to available experience in the blasting industry, direct minor and major structural damage to 1-2 story residential houses without resonant structural responses were observed in the velocity range of 33-191 mm/s for frequencies of 2 to $5 \mathrm{~Hz}$ and in the velocity range of $102-254 \mathrm{~mm} / \mathrm{s}$ for frequencies of 60 to 450 $\mathrm{Hz}$, Siskind [7]. Construction equipment does not generate low frequency ground vibrations for triggering resonant horizontal house vibrations. It is one more reason of irreconcilability of the USBM limits to construction vibrations. Nevertheless, vibratory pile drivers may generate resonant vertical floor vibrations. It could be one of the causes of damage to residential houses. The major cause of damage to structures from construction vibrations is dynamic settlement. Ground and foundation settlements triggered by small ground vibrations in diverse sand soils may occur at various distances from the source. This phenomenon and liquefaction are different because liquefaction can be triggered by relatively high ground vibrations with PPV of about $100 \mathrm{~mm} / \mathrm{s}$, but ground vibrations with PPV of 20-40 times smaller may be the cause of dynamic settlement in vulnerable soils. According to
Lacy and Gould [8], the peak particle velocity of $2.5 \mathrm{~mm} / \mathrm{s}$ could be considered as the threshold of possible significant settlements at vulnerable sandy sites. For assessment of vibration effects of construction vibrations on houses, the authors used the USBM limits and concluded, "Forensic investigation results revealed that ground vibrations from construction operations could not be the cause of alleged damages to the houses and that stability of nearby structure was not in jeopardy." This conclusion is wrong and misleading. As it was shown above, the soil deposits to depth of 9.0 m consisted of moist poorly graded loose to medium dense slightly silty sand in the neighborhood area of the TV4 construction site. Ground vibrations with PPV between 4.6-11.4 mm/sec measured at that area during construction operations are substantially higher than $2.5 \mathrm{~mm} / \mathrm{s}$, and they could trigger settlement in sandy soils. Therefore, dynamic settlement has to be considered as the major cause of damage to houses located in the neighborhood area of the TV4 and TV5 construction sites.

\section{Acknowledgement}

None.

\section{Conflict of Interest}

The paper is based on the writer report prepared in 2004 and referenced in the paper. Publication of the report results in that time was perfectly reasonable. Unfortunately, the paper was published in 2016 after the new obtained results had shown that the USBM vibration limits have nothing to do with construction vibrations. The writer must say that he has no connection with the reviewed paper.

\section{References}

1. Saxena DS, Vaddu P, Saxena A (2016) Forensic Engineering, Legal Considerations, and Property Damage Assessment from Construction Vibrations, Geotechnical Forensic Engineering, Rao VVS, Sivakumar Babu GL (Eds.), Springer, India, 521-533.

2. Svinkin MR, Saxena DS (2004) Vibration Monitoring, Data Evaluation, and Engineering Consultation Services Report Conducted on Existing Residences of 20 Claimants Seville Drive Stormwater Treatment/ Enhancement Project (Clark Site). Pensacola Escambia County Florida.

3. Siskind DE, Stagg MS, Kopp JW, Dowding CH (1980) Structure Responsa and Damage Produced by Ground Vibrations from Surface Blasting. RI 8507 US Bureau of Mines Washington DC.

4. Svinkin MR (2008) Soil and structure vibrations from construction and industrial sources. OSP 8 Proceedings of the Sixth International Conference on Case Histories in Geotechnical Engineering (CD-ROM) Omni Press Madison Wisconsin.

5. Svinkin MR (2013) Forensic engineering of construction vibrations. Forensic Engineering ICE 166 FE2: 81-93.

6. Svinkin MR (2015) Tolerable limits of construction vibrations. Practice Periodical on Structural Design and Construction ASCE 20(2): 04014028-1 - 7 .

7. Siskind DE (2000) Vibration from Blasting. International Society of Explosives Engineers Cleveland Ohio.

8. Lacy HS, Gould JP (1985) Settlement from pile driving in sand. Proceedings of Symposium on Vibration Problems in Geotechnical Engineering, Gazetas G, Selig ET (Eds.), ASCE New York 152-173. 